\title{
THE
}

\section{Measuring Mean Velocities with POGO}

\author{
Hans Thomas Rossby \\ University of Rhode Island, trossby@uri.edu \\ J. Fontaine \\ University of Rhode Island \\ J. Hummon \\ University of Rhode Island
}

Follow this and additional works at: https://digitalcommons.uri.edu/gsofacpubs

\section{Citation/Publisher Attribution}

Rossby, T., Fontaine, J., \& Hummon, J. (1991). Measuring Mean Velocities with POGO. J. Atmos. Oceanic Technol., 8(5), 713-717. doi: 10.1175/1520-0426(1991)0082.0.C0;2

Available at: http://dx.doi.org/10.1175/1520-0426(1991)0082.0.c0;2

This Article is brought to you for free and open access by the Graduate School of Oceanography at DigitalCommons@URI. It has been accepted for inclusion in Graduate School of Oceanography Faculty Publications by an authorized administrator of DigitalCommons@URI. For more information, please contact digitalcommons-group@uri.edu. 


\title{
Measuring Mean Velocities with POGO
}

\author{
T. ROSSBY, J. FONTAINE AND J. HUMMON \\ Graduate School of Oceanography, University of Rhode Island, Narragansett, Rhode Island
}

9 July 1990 and 27 February 1991

ABSTRACT

\begin{abstract}
POGO is a simple technique for measuring water transport between the surface and some preselected depth. Equipped with a 12-kHz pinger for tracking and range measurement, a xenon flasher for nighttime relocation, and a VHF beacon for daytime recovery, it has been used over 200 times in the Gulf Stream to measure volume transport and to provide a reference velocity (transport) for geostrophic calculations from pairs of hydrographic stations. This note gives a brief technical description of POGO and how it is used. Loran $C$ was used for navigation in this study, but with the advent of the Global Positioning System (GPS), POGO can be used worldwide.
\end{abstract}

\section{Introduction and principle of operation}

POGO is a modern version of the dropsonde technique that was developed by Richardson and Schmitz (1965) at Nova University and applied extensively to the Gulf Stream system (e.g., Richardson et al. 1969; Schmitz and Richardson 1968; Barrett and Schmitz 1971). All that is required is a device that sinks to a preset depth and returns to the surface at a steady rate. The horizontal displacement between the release and surface points divided by the time underwater is the vertically averaged mean velocity. The position at launch is determined from Loran C, and the surfacing point is obtained from the ship's Loran $\mathrm{C}$ position in addition to the vector from the ship to POGO as soon as it is sighted. Since POGO is usually not spotted immediately (in daytime), it is necessary to measure its surface drift (from successive sightings) so that its displacement on the surface between surface and sight time can be estimated. Figure 1 gives a perspective view of how POGO is used. The principal difference between the Nova operation and ours is the necessary use of Loran C instead of Decca HiFix, which, although more accurate, is limited to nearshore operation. To compensate for the loss in navigational precision, we let POGO sink and rise more slowly, thereby increasing the horizontal displacement. The distance between the ship and POGO is measured acoustically. POGO transmits a pulse exactly every $4 \mathrm{~s}$. The pulses are recorded onboard ship on a precision graphic recorder with a crystal-controlled sweep.

Corresponding author address: Dr. T. Rossby, University of Rhode Island, Graduate School of Oceanography, Narragansett Bay Campus, Narragansett, RI 02882-1197.

\section{POGO}

The instrument has the following functions: 1) an acoustic pinger for tracking, relocation, and distance measurement; 2) a pressure gauge, with which its depth is measured and telemetered once a minute; 3 ) a xenon flasher for spotting at night; and 4) a VHF beacon for approximate bearing to aid in sighting the instrument in daytime. All of the electronics are housed in a 1.67$\mathrm{m}$-long borosilicate (Pyrex) glass pipe with $0.075-\mathrm{m}$ inner diameter. Figure 2 shows the layout.

\section{a. Mechanical characteristics}

The glass pipe is closed and rounded at one end and ground flat (and annealed to remove microcracks and stress centers due to the grinding) at the other. An aluminum endplate closes the pipe. It is attached to the glass pipe with a bead of silicone-based adhesive (RTV) applied at the outside junction between the pipe and the endplate. Between the two is a thin $(0.025 \mathrm{~cm})$ sheet of Teflon for stress relief due to changes in pressure. At the closed (upper) end of the pipe is a polypropylene "hat" and snatch arrangement so that it can be hooked and recovered with a light line. Two "wings" are attached (with RTV) to either side of the pipe. They force the pipe to rotate while it is in motion so that any tendency for the pipe to kite to the side is canceled out. (In a motionless ocean the pipe should return to the same point.) The acoustic pinger is a piezoelectric ceramic ring tuned to $12 \mathrm{kHz}$. It sits inside a polyethylene boot filled with oil. The pressure gauge is also attached to the endplate on the inside. Ambient pressure is communicated through the oil boot. The battery pack sits at the lower end of the pipe to keep the center of gravity well below the center of buoyancy. We chose a glass pipe because it is inexpensive, strong, 


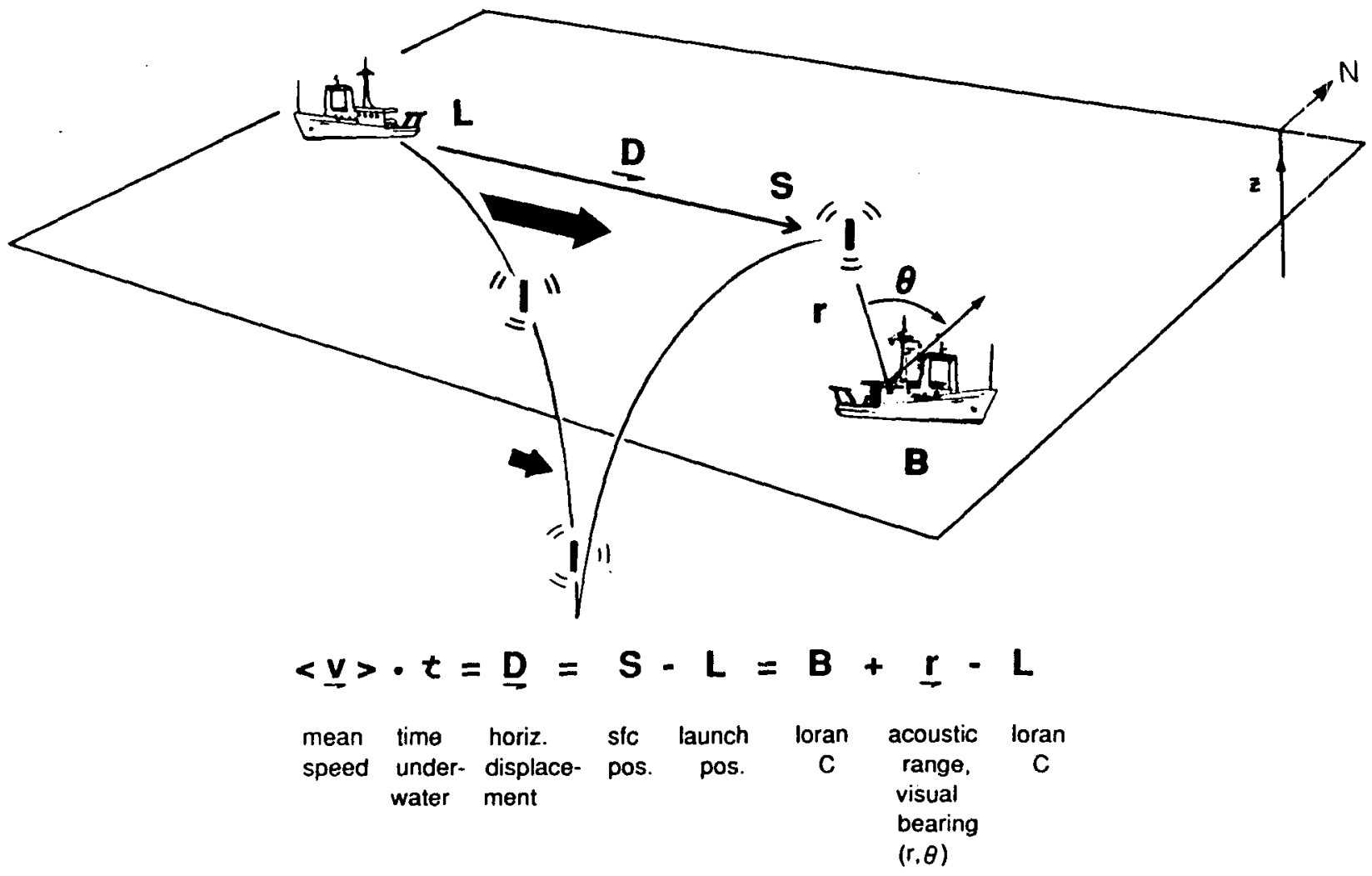

(Typical numbers: $\mathrm{D}=\mathbf{1 - 2} \mathrm{km}, \mathrm{r}=\mathbf{0} .2-0.8 \mathrm{~km}$ )

FIG. 1. Perspective view of the POGO operation. The instrument is released at $\mathrm{L}$ and surfaces at $\mathrm{S}$. Range $r$ and bearing $\Theta$ from the ship to POGO complete the vector measurement of displacement.

corrosion-free and transparent. It permitted us to put a low-cost flasher and radio inside the pipe, instead of purchasing separately housed radios and flashers and attaching them to the outside.

\section{b. Electrical characteristics}

All the electronics, including radio, flasher, and battery, are mounted on standoffs along a single PVC spar that runs the length of the pipe. The flasher and radio are mounted uppermost. The main circuit board includes the voltage regulator, an m6805 CMOS microprocessor and memory, and a push-pull power amplifier to drive the pinger. All functions are controlled by the microprocessor. It times the pinger amplifier, makes the pressure measurement, telemeters the measurement as a pressure proportional variable time delay acoustic pulse, and powers the flasher and radio if the pressure drops below a certain threshold on the assumption that it is at the surface. Figure 3 shows schematically the electrical functions. To ensure that the timing of the acoustics is accurate, a temperature compensated oscillator with a stability of 1 part in $10^{7}$ is used, but lesser accuracy would suffice.

Each acoustic ping is $10 \mathrm{~ms}$ long. They are transmitted every $4 \mathrm{~s}$. The telemetry consists of a second, delayed set of 12 pulses that are transmitted each minute. The delay between the main telemetry pings is linearly proportional to pressure. The pinger is not operated during the pressure measurement to minimize interference. The transmitted power is about $30 \mathrm{~W}$. Figure 4 shows a typical PGR recording aboard ship of the acoustic signaling from POGO. The instrument is powered up by removing a magnet that controls a reed switch in series with the $15-\mathrm{V}$ alkaline battery paik.

\section{c. Release}

The depth of each cast is preset through a mechanical release. This technique is borrowed directly from Schmitz and Richardson (1968). The drop weight or ballast is suspended underneath POGO by means of a line to the pressure-actuated release. The release consists of a stainless steel piston and cylinder. The pistion is kept in its outer position by means of a brass screw that is held in place by a bridge that rests on the cylinder. As the pressure (depth) increases, the force on the piston increases, but it is held in place by the brass screw. When the pressure exceeds a critical value, the head of the brass screw shears off and lets go of the ballast line. By turning the neck of the screw to the appropriate diameter, it is possible to select the release 


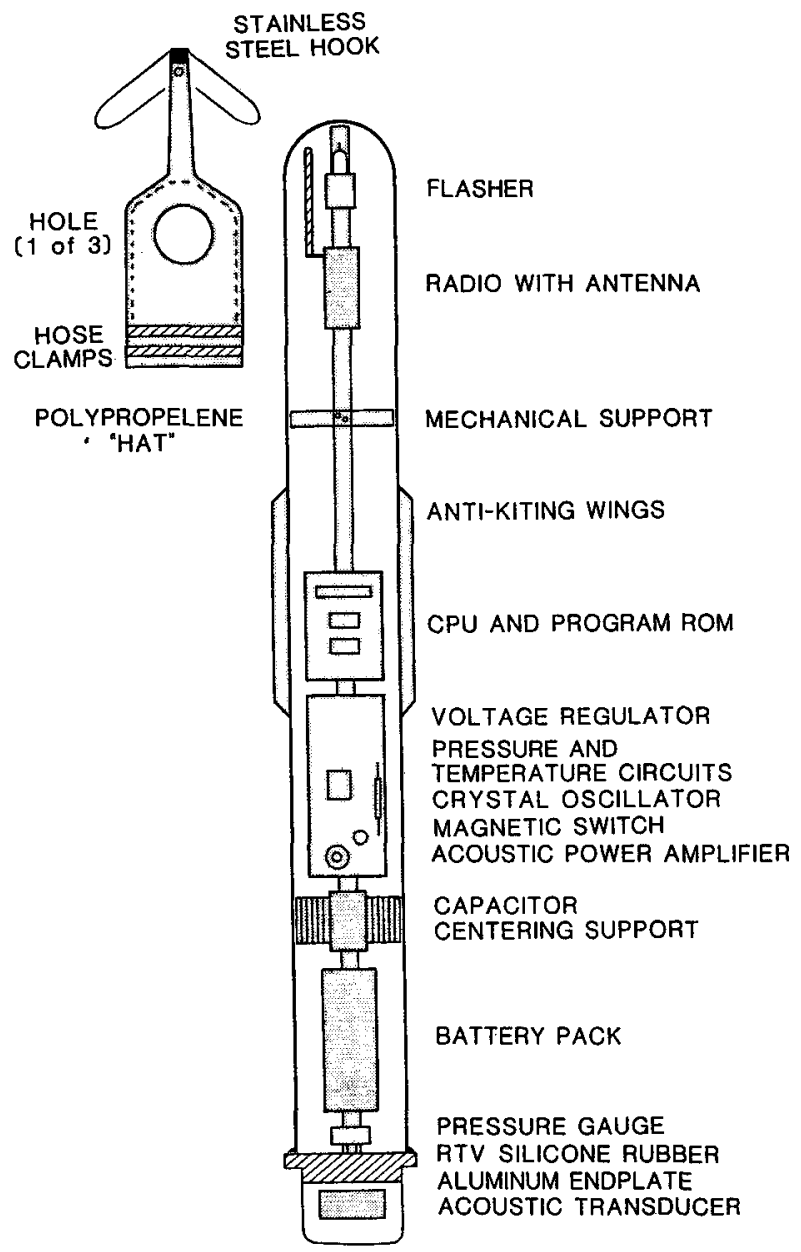

FIG. 2. Mechanical layout of POGO. The heavy items such as the pinger, the battery, and the electronics are concentrated towards the bottom to give the instrument vertical stability. The small protuberances on the side of the pipe are little "wings" that cause POGO to rotate while sinking and rising. The pressure release assembly and dropweight are clipped on to a bridle below the acoustic pinger (not shown).

depth with an uncertainty of 5\%-10\%. Better accuracies are possible if necessary. The actual release depth is known from the pressure telemetry to $1 \%-2 \%$ accuracy. We found it convenient to make dropweights using cloth bags in which we pour discarded steel bolts or scrap to achieve the desired weight. The instrument itself weighs about $10 \mathrm{~kg}$. Its negative weight in water is about $0.3 \mathrm{~kg}$, and during ascent is about $1.2 \mathrm{~kg}$ positively buoyant. The buoyancy of the float is adjusted so that the POGO floats reasonably high in the water for visibility and ease of pickup.

\section{d. Operational}

We built five instruments for our work in the Gulf Stream. Because of their glass construction, we assumed we would break several of them in the course of our work. This turned out to be much less of a hazard than anticipated, even though many times during recovery, POGO would scrape along the side of the ship. We believe the recovery "hat" on top and the winglets on the side provided some protection. Also, the diameter of the aluminum endplate is somewhat larger than that of the pipe. In more than 200 recoveries we broke only one pipe.

POGO was hand launched off the stern of the ship, usually during the winching up phase of a CTD cast. It was followed continuously on the PGR recorder. It was ballasted to sink to $1000 \mathrm{~m}$ in about $25 \mathrm{~min}$. After dropping ballast it returned to the surface in about onethird the time. Its displacement in the horizontal could be as much as $2000 \mathrm{~m}$ in the center of the Gulf Stream. We tried to maneuver the ship so we would be within $300 \mathrm{~m}$ when it surfaces. This did not always work; the difficulty is that research vessels are equipped with only one hydrophone, so it is not possible to get acoustic bearing information. To do this would require at least two hydrophones mounted thwartships. After POGO was sighted, it was allowed to drift on the surface for at least as long as it took to sight it so that an accurate correction for surface drift could be made. Pickup was made with a long pole with a rope loop at the end.

\section{e. Errors}

There are two different sources of error in estimating velocity. The first is due to the Loran $\mathrm{C}$ system. The second is the sighting error associated with computing the vector from POGO to the ship when the instrument surfaces. The short-term repeatability ( $30 \mathrm{~min})$ of position using Loran $C$ in areas of good coverage appears to be better than $30 \mathrm{~m}$. This means that the accuracy of velocity due to radio navigation errors should be $\left(30^{2}+30^{2}\right)^{1 / 2} \mathrm{~m} / 40 \mathrm{~min}=0.018 \mathrm{~m} \mathrm{~s}^{-1}$. This is very good and can be made better by extending the integration time (time submerged).

In reference to the sighting errors, the measurement itself is not difficult, but it is important to make sure that range, bearing, and ship's position are noted at the same time. Range is measured very accurately acoustically and usually to better than $10 \mathrm{~m}$. The exception is when the ship is moving fast at sighting time and there is an offset in time between the log of the Loran $C$ position and when the range is noted. At $5 \mathrm{kt}$ (we were rarely moving faster than this) and a 10-s offset in notation time, the error would be $25 \mathrm{~m}$. The single most serious factor is the estimate of bearing. In daytime the instrument could not be sighted at more than 2-300 $\mathrm{m}$ at best, whereas at night the flasher could be sighted at any distance. Bearing was estimated to within the nearest $5^{\circ}$, which is $0.1 \mathrm{rad}$. The median range at sight was between 200 and $400 \mathrm{~m}$, which would mean a possible position error of $15 \mathrm{~m}$. This is acceptable, but at a $1000-\mathrm{m}$ range it would be $50 \mathrm{~m}$. Fortunately, the number of sightings at ranges greater than $500 \mathrm{~m}$ were very few, and these were all done at night when the sighting was easier and the bearing estimates were, therefore, somewhat better. In summary, the position of the POGO at sight was estimated from the ship's position plus the vector from the ship to 


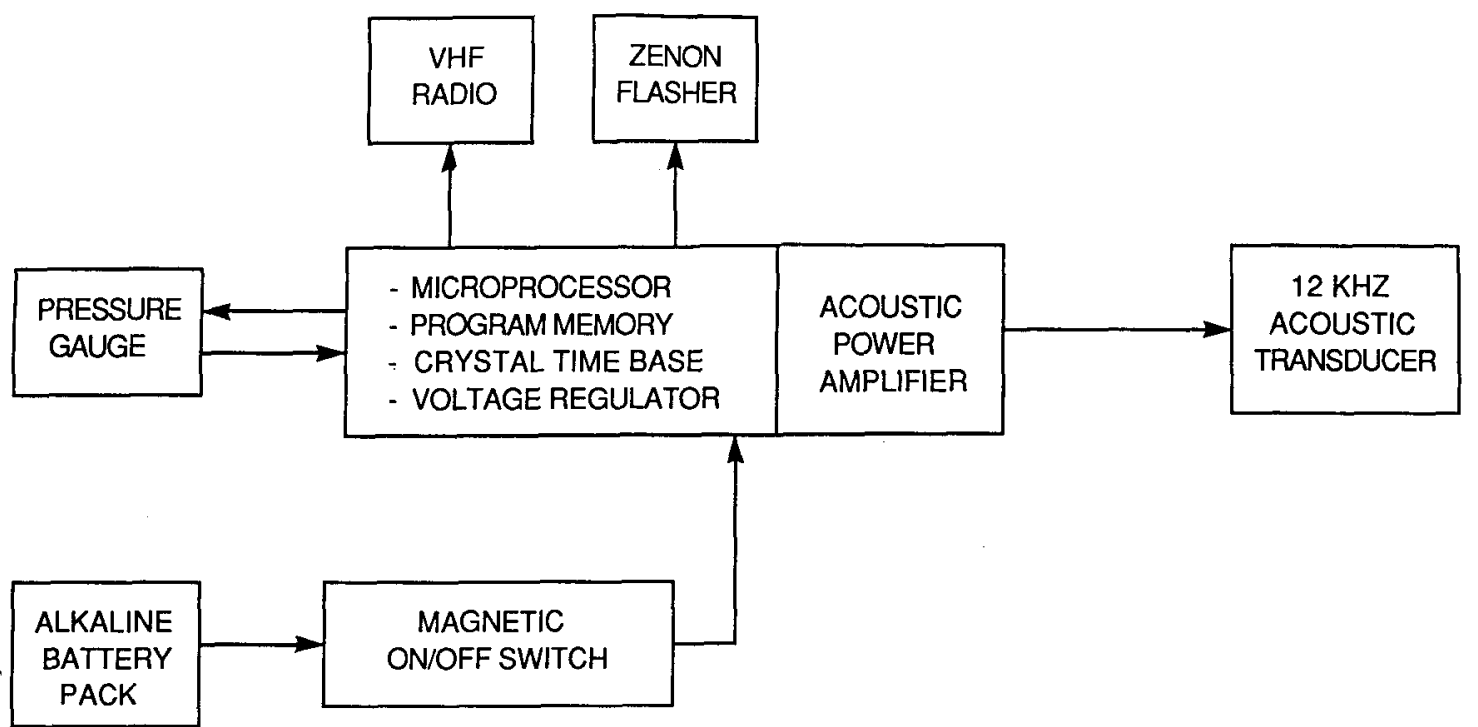

FIG. 3. Block diagram of all the electrical functions. The microprocessor controls all activity once the POGO is powered up. (This is done by removing a magnet that connects the battery.)

POGO, the greatest uncertainty of which was due to the bearing measurement. The combined error in estimating the displacement is thus $\left(30^{2}+30^{2}+15^{2}\right)^{1 / 2}$ $=45 \mathrm{~m}$. Dividing this into $40 \mathrm{~min}$ for a typical submerged time equals $0.02 \mathrm{~m} \mathrm{~s}^{-1}$. Against the conservative numbers for the Loran $C$ uncertainties, the sighting error is not a major contribution. Since POGO

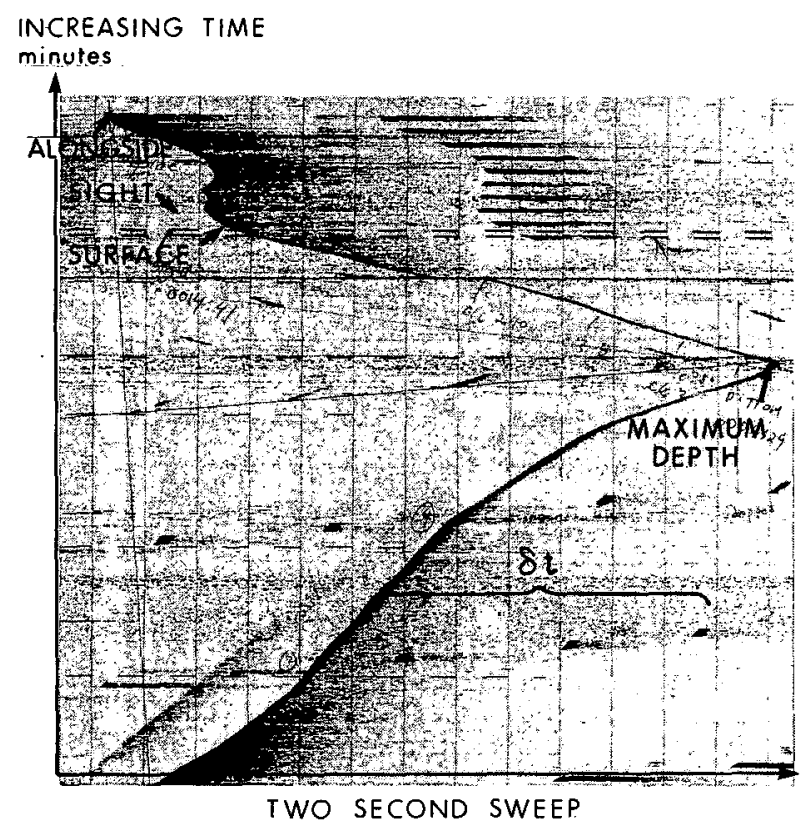

FIG. 4. A typical PGR recording of all the signals as recorded onboard. We used a Raytheon PTR 105 (receive only) with a hullmounted Edo Western transducer. The recorder was a Raytheon UGR in the 2-s sweep (the 4-s signal appears on every other sweep). The dark spots with the delay $\delta t$ are the telemetry pulses. As the float sinks, the delay increases beyond $2 \mathrm{~s}$ and the pulses reappear on the left side in successive 2 -s windows. is not always sighted immediately in daytime, we track the instrument on the surface for at least as long as it drifted before it was spotted so that we get a good drift estimate. This is then used to back calculate where it surfaced. The drift vectors use a third Loran C estimate when the POGO is alongside the ship, just before pickup. The most conservative estimate would be to assume it contributes another independent error leading to $\left(30^{2}+30^{2}+30^{2}\right)^{1 / 2}$ or $52 \mathrm{~m} / 40 \mathrm{~min}=0.022$ $\mathrm{m} \mathrm{s}^{-1}$. This is still a small error. We believe most vectors have this kind of quality. Unfortunately, the method depends upon close timing and coordination. A slip-up could go undetected during the observational

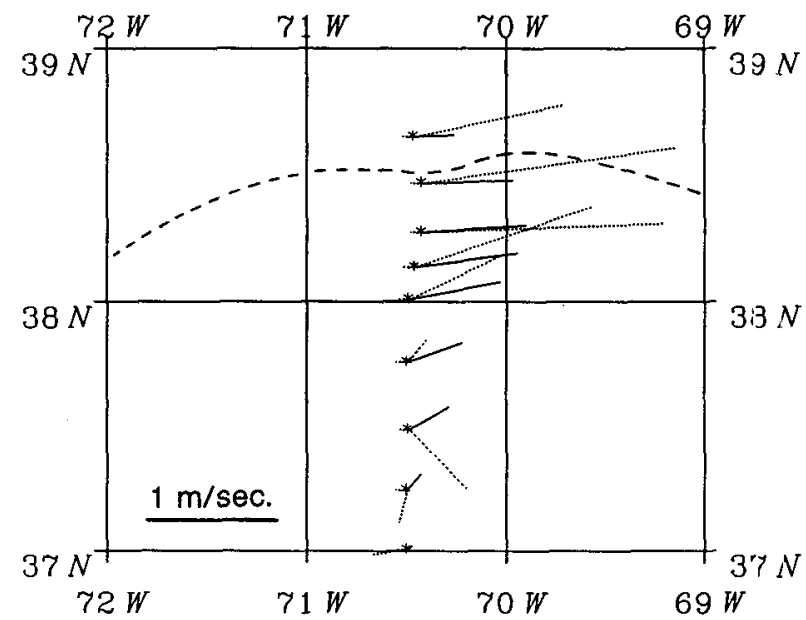

FIG. 5. Location of the CTD/POGO section across the Gulf Stream 29 January 1990 . The dashed line indicates the approximate parh of the surface thermal front at the time. The heavy vectors indicats: the mean velocity between the surface and $1100 \mathrm{~m}$, the dotted line the surface velocities as observed by POGO while drifting on the surlace. 

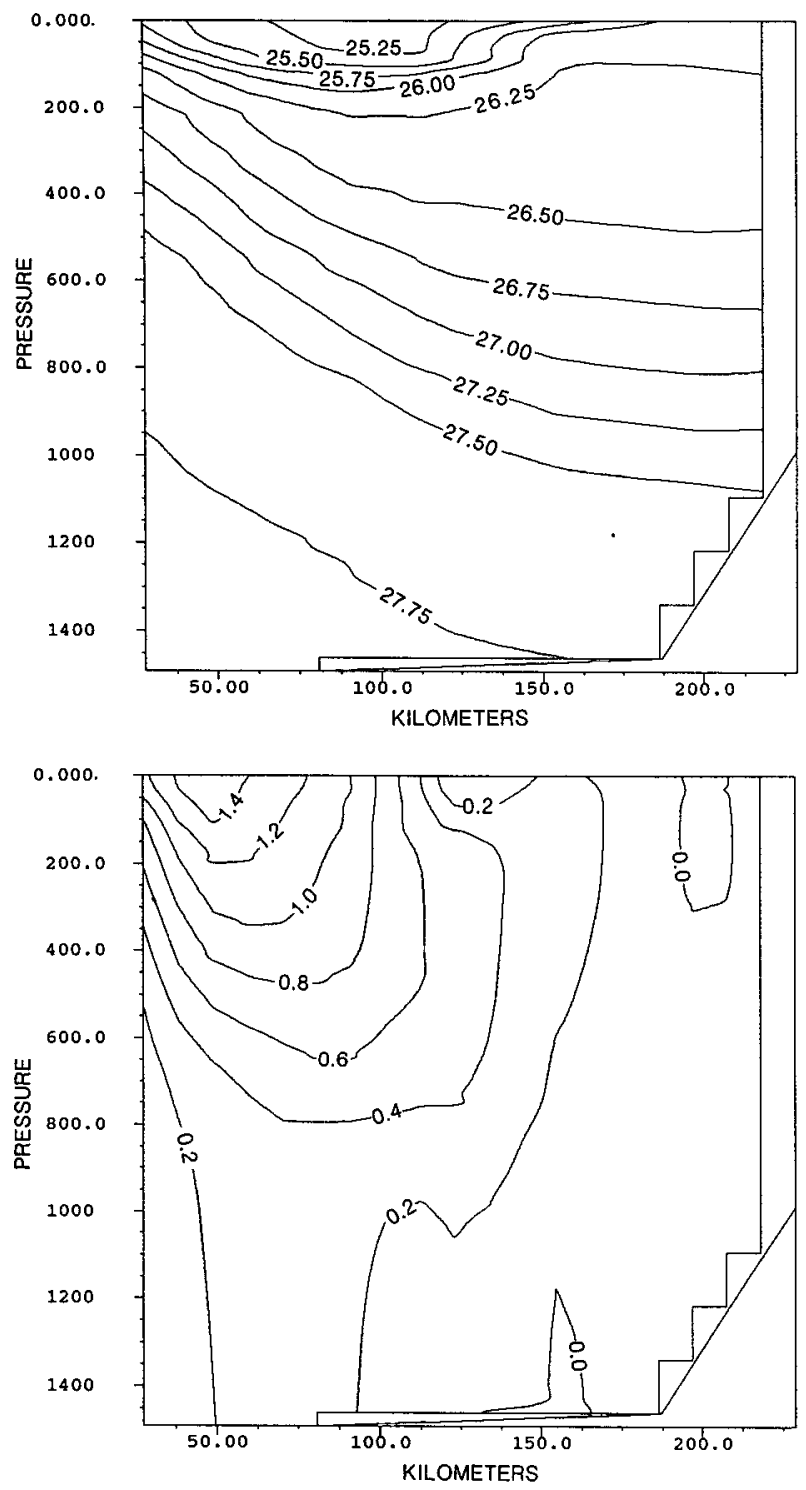

Fig. 6. Contour plot of sigma- $t$ from the CTD stations. (a) Contour plot of absolute geostrophic velocity (b) constructed from the dynamic height field and the POGO transport vectors. The contours are in meters per second, and the depth is shown as pressure in decibars.

phase, and only later, if it was gross enough to be obvious, be detected and corrected or deleted.

\section{A typical POGO section}

In January 1990 we took a CTD/POGO section across the Gulf Stream near $70^{\circ} 30^{\prime} \mathrm{W}$. Figure 5 shows the locations of the CTD/POGO sites. The heavy vectors show the average velocity between the surface and about $1100 \mathrm{~m}$, and the light vectors show the surface velocity. This section crossed the current near a meander crest, and this is indicated by the dashed line. Figure $6 \mathrm{a}$ is a contour plot of density computed from the CTD casts. The dynamic height anomaly is computed for each cast. These are then differenced pairwise to obtain the geostrophic velocity field relative to the surface. By averaging the corresponding POGO drops for the two CTDs, we have a good measure of the absolute mass transport. The relative velocity profile can than be shifted to include this transport. This, then, becomes the absolute velocity profile for each pair. It should be recalled that while the POGO velocity is a vector, only the component normal to the section is of use here. The velocity profile along the section remains unknown. The geostrophic velocity normal to the section is contoured in Fig. 6b. No adjustment was made here for possible curvature effects (i.e., gradient wind balance) since the radius of curvature was large at the time (and not well known).

\section{Summary}

POGO is a simple means to render geostrophic calculations of velocity absolute. With the advent of the Global Positioning System, it can be used worldwide. The accuracy of the velocity profiles depends on several factors. In our application, the absolute accuracy is about $\pm 0.02 \mathrm{~m} \mathrm{~s}^{-1}$ (POGO) and $\pm 0.05-0.1 \mathrm{~m} \mathrm{~s}^{-1}$ for the dynamic method in the fast current of the Gulf Stream (Johns et al. 1989). In the open ocean the velocities are much smaller than in the stream. If a POGO drop were allowed to take $2 \mathrm{~h}$ during a deep-ocean hydrocast, say, very accurate measurements of transport and hence the geostrophic velocity field could be obtained as well. The limiting factor for accuracy may then be high-frequency velocity fluctuations, particularly barotropic tidal currents.

Acknowledgments. We wish to thank Mr. Don Dorson, BathySystems, Exeter, RI, for his help with the electronics and programming of the microprocessor. Mr. Al Morton of Oceanographic Instrument Systems, N. Falmouth, MA, provided the endplate with the acoustic pinger. Mrs. Kathy Schultz Tokos, Dr. Amy Bower, Dr. A. Mariano, and others gave valuable advice on how to make the POGO operations work smoothly at sea. We have used POGO on three different cruises with the R/V Endeavor. We would like to thank the captain and crew for their constant and cheerful help at all times!

\section{REFERENCES}

Barrett, J., and W. Schmitz, 1971: Transport float measurements and hydrographic station data from three sections across the Gulf Stream near $67^{\circ} \mathrm{W} ; \mathrm{R} / \mathrm{V}$ Crawford cruise 168, June-July 1968. Woods Hole Oceanographic Institution Tech. Rep., WHOI-71-66, $94 \mathrm{pp}$.

Johns, E., D. R. Watts and T. Rossby, 1989: Test of geostrophy in the Gulf Stream. J. Geophys. Res., 94, 3211-3222.

Niiler, P. P., and W. S. Richardson, 1973: Seasonal variability of the Florida Current. J. Mar. Res., 31, 144-167.

Richardson, W. S., and W. J. Schmitz, Jr., 1965: A technique for the direct measurement of transport with application to the Straits of Florida. J. Mar. Res., 23, 172-185.

- and P. P. Niiler, 1969: The velocity structure of the Florida Current from the Straits of Florida of Cape Fear. Deep-Sea Res., 16(suppl.), 255-231.

Schmitz, W. J., and W. S. Richardson, 1968: On the transport of the Florida Current. Deep-Sea Res., 15, 679-693. 